УДК 796.015.132:796.422.14

DOI https://doi.org/10.26661/2663-5925-2020-1-17

\title{
МОДЕЛЬНІ ХАРАКТЕРИСТИКИ ФІЗИЧНОЇ ПІДГОТОВЛЕНОСТІ ВИСОКОКВАЛІФІКОВАНИХ БІГУНІВ НА СЕРЕДНІ ДИСТАНЦЇ̈
}

\author{
Павлось О. О. \\ кандидат наук з фізичного виховання і спорту, дочент, \\ дочент кафедри легкої атлетики \\ Львівський державний університет фізичної культури імені Івана Боберського \\ вул. Костюшка, 11, Львів, Украӥна \\ orcid.org/0000-0002-0679-7909 \\ olha_slisenko@ukr.net \\ Хохла А. I. \\ кандидат наук з фізичного виховання і спорту, \\ дочент кафедри фізичного виховання та спортивної медицини \\ Львівський національний медичний університет імені Данила Галицького \\ вул. Пекарська, 69, Львів, Україна \\ orcid.org/0000-0002-6877-9255 \\ Павлось Р. М. \\ старший викладач кафедри фізичного виховання \\ Національний університет «Львівська політехніка» \\ вул. Степана Бандери, 12, Львів, Україна \\ orcid.org/0000-0002-5303-3581 \\ ryslan_pavlos@ukr.net
}

Ключові слова: легка
атлетика, фізична
підготовленість, біг
на середні дистанції,
бігуни високої кваліфікацї.
Метою дослідження було удосконалити моделі фізичної підготовленості висококваліфікованих бігунів. Об'єкт дослідження - фізична підготовленість бігунів на середні дистанції на етапі максимальної реалізації індивідуальних можливостей. Предмет дослідження - показники фізичної підготовленості висококваліфікованих бігунів на середні дистанції.

Методи дослідження - теоретичний аналіз та узагальнення даних наукової та методичної літератури; документальні методи; педагогічне спостереження (використовуючи інструментальні методики: антропометрія, хронометрія); методи математичної статистики.

Наукова новизна. У цій роботі доповнено та розширено відомості щодо інформативності показників фізичної підготовленості бігунів на середні дистанції. На підставі здійсненого наукового аналізу розроблено кваліфікаційні моделі фізичної підготовленості висококваліфікованих бігунів на середні дистанції.

Практичне значення - результати дослідження можливо використовувати у підготовці бігунів на середні дистанції.

Результати. Кількісні значення таких характеристик, як біг 60 м, 200 м, 800 м, 5000 м, стрибок у довжину з місця та потрійний стрибок із місця, дають змогу рекомендувати в якості модельних показників фізичної підготовленості висококваліфікованих бігунів на середні дистанції.

Розроблено кваліфікаційну модель фізичної підготовленості висококваліфікованих бігунів на середні дистанції для досягнення результату з бігу на 1500 м - 3.44,15 хв \pm 4,38 с. Модельним характеристикам фізичної підготовленості висококваліфікованих бігунів на середні дистанції відповідають 
такі показники: зріст - $176 \mathrm{~cm} \pm 5,6$ см, вага - 61 кг \pm 4 кг, зросто-ваговий індекс - 15,4 \pm 5 від. од., біг $60 \mathrm{~m}-7,3 \mathrm{c} \pm 0,3 \mathrm{c}$, біг $200 \mathrm{~m}-24,3 \mathrm{c} \pm 1,2 \mathrm{c}$, біг $800 \mathrm{м}-1.51,7 \mathrm{xв} \pm 2,9$ с, стрибок у довжину з місця $-2,64 \mathrm{M} \pm 0,21 \mathrm{M}$, потрійний стрибок із місця - 7,77 м $\pm 0,59$ м, біг 5000 м - 14,10 хв \pm 67 с.

Визначено, що зростом та вагою бігуни на середні дистанції високої кваліфікації відрізняються, про що свідчить і коефіцієнт варіації зросто-вагового індексу (32\%). Швидкісні, швидкісно-силові показники та показники швидкісної та загальної витривалості повинні бути на високому рівні: біг 60 м - 3,4\%, потрійний стрибок 3 місця - 7,6\%, стрибок у довжину 3 місця $-7,8 \%$, біг на 800 м - 2,6\%, біг на 5000 м - 7,9\%.

\title{
MODEL CHARACTERISTICS OF PHYSICAL PREPAREDNESS OF HIGHLY QUALIFIED MIDDLE DISTANCE RUNNERS
}

\author{
Pavlos O. O. \\ PhD in Physical Education and Sports, Associate Professor, \\ Senior Lecturer at the Department of Athletics \\ Lviv State University of Physical Culture named after Ivan Bobersky \\ Kostiushka str., 11, Lviv, Ukraine \\ orcid.org/0000-0002-0679-7909 \\ olha_slisenko@ukr.net \\ Hohla A. I. \\ PhD in Physical Education and Sports, \\ Associate Professor at the Department of Physical Education and Sport Medicine \\ Danylo Halytsky Lviv National Medical University \\ Pekarska str., 69, Lviv, Ukraine \\ orcid.org/0000-0002-6877-9255 \\ sportalla@ukr.net \\ Pavlos R. M. \\ Assistant Professor at the Department of Physical Education \\ Lviv Polytechnic National University \\ Bandera str., 12, Lviv, Ukraine \\ orcid.org/0000-0002-5303-3581 \\ ryslan_pavlos@ukr.net
}

Key words: physical preparedness, run on middle distances, high qualification runners.
The aim of the study is to improve the models of physical preparedness of highly qualified runners. The object of research physical preparedness of runners on medium distances at the stage of maximum realization of individual possibilities. The subject of research is the indicators of physical preparedness of highly qualified runners for medium distances.

Methods of research - theoretical analysis and generalization of literary sources; documentary methods; pedagogical observation using instrumental techniques: anthropometry, timekeeping, methods of mathematical statistics.

Scientific novelty. In this paper, the information on the informativeness of indicators of physical preparedness of runners for medium distances is supplemented and expanded. Qualitative models of physical preparedness 
of highly qualified runners on medium distances are developed on the basis of the performed scientific analysis.

The practical significance: the results of the study may be used in the preparation of runners for medium distances.

Results. The quantitative values of such characteristics as running $60 \mathrm{~m}, 200 \mathrm{~m}, 800 \mathrm{~m}, 5000 \mathrm{~m}$, jump in length from the place and a triple jump from place, allows to recommend as average modeling indicators of physical preparedness of highly qualified runners on medium distances. A qualitative model of physical preparedness of highly qualified runners on average distances was developed for achievement of the result from running at $1500 \mathrm{~m}-3: 44,15 \mathrm{~min} \pm 4,38 \mathrm{~s}$.

Model characteristics of physical preparedness of highly qualified runners for medium distances correspond to the following indices: height $-176 \mathrm{~cm}$ $\pm 5.6 \mathrm{~cm}$, weight $-61 \mathrm{~kg} \pm 8 \mathrm{~kg}$, height-weighted index $-15.4 \pm 5$, running $60 \mathrm{~m}-7.3 \mathrm{~s} \pm 0.3 \mathrm{~s}$, running $200 \mathrm{~m}-24.3 \mathrm{~s} \pm 1.2 \mathrm{~s}$, running $800 \mathrm{~m}-1: 51.7$ $\min \pm 2.9 \mathrm{~s}$, jump in length from places $-2.64 \mathrm{~m} \pm 0.21 \mathrm{~m}$, triple jump from place $-7.77 \mathrm{~m} \pm 0.59 \mathrm{~m}$, running $5000 \mathrm{~m}-14: 10,0 \mathrm{~min} \pm 0,67$.

It is determined that the height and weight of the runners on the average distance of high qualification are different, as indicated by the coefficient of variation of the height-weighted index (32\%). High-speed, speed-power indicators and indicators of high-speed and overall endurance should be at a high level: running $60 \mathrm{~m}-3,4 \%$, triple jump from place $-7,6 \%$, jump from a place $-7,8 \%$, running on $800 \mathrm{~m}-2.6 \%$, running at $5000 \mathrm{~m}-7.89 \%$.

Біг на середні дистанції користується великою популярністю як у багатьох країнах світу, так і в Україні. Проте сучасні досягнення українських бігунів на середні дистанції суттєво поступаються результатам провідних спортсменів світового рівня.

Ефективне управління тренувальним процесом на сучасному етапі розвитку теорії та методики підготовки спортсменів вимагає методично правильної організації комплексного контролю за функціональним станом організму, розвитком рухових якостей під впливом тривалих фізичних навантажень [1]. Високі показники фізичної підготовленості $є$ функціональним фундаментом для розвитку спеціальних фізичних якостей, для ефективної роботи над удосконаленням інших сторін підготовленості спортсменів - технічної, тактичної, психічної [2].

Показники фізичної підготовленості бігунів на середні дистанції вивчали різні фахівці у різні роки. Для оцінювання рівня фізичної підготовленості автори рекомендують використовувати велику кількість різноманітних контрольних вправ 3 урахуванням зросто-вагових характеристик бігунів [3, 4, 5]. На основі аналізу літературних джерел було зроблено висновок, що нині питання фізичної підготовленості бігунів на середні дистанції є досить актуальним.

Враховуючи актуальність цього питання, метою роботи була спроба удосконалити моделі фізичної підготовленості висококваліфікованих бігунів на середні дистанції.

\section{Завдання:}

1. Розробити кваліфікаційну модель фізичної підготовленості висококваліфікованих бігунів на середні дистанції.

2. Порівняти показники фізичної підготовленості бігунів на середні дистанції на етапі максимальної реалізації індивідуальних можливостей.

Для розробки кваліфікаційної моделі фізичної підготовленості висококваліфікованих бігунів на середні дистанції ми визначали рівень їх фізичної підготовленості. Тестування обирали, спираючись на їх надійність і ступінь кореляції з бігом на 1500 м. Окрім цього, критерієм вибору тестів стало застосування їх безпосередньо у підготовці усіма спортсменами групи педагогічного спостереження [6].

До педагогічного спостереження було залучено 10 бігунів на середні дистанції, рівень спортивної кваліфікації - майстер спорту України, вік - від 22 до 31 року. Учасниками педагогічного спостереження стали багаторазові переможці та призери чемпіонатів і кубків України, призери та учасники чемпіонатів і кубків Європи, учасники чемпіонатів світу, а саме Володимир Киц, Юрій Кіщенко, Олег Каяфа, Артем Казбан, Іван Стребков, Богдан-Іван Городиський, Юрій Вихопень, Роман Ростикус, Микола Нижник і Сергій Шевченко.

У таблиці 1 наведені результати, отримані під час проведення дослідження.

3 огляду на отримані результати та дані інформаційних джерел було розроблено кваліфікаційну модель фізичної підготовленості висококваліфікованих бігунів на середні дистанції для 
досягнення результату 3 бігу на 1500 м $3.44,15$ хв $\pm 4,38$ с. Модельним характеристикам фізичної підготовленості висококваліфікованих бігунів на середні дистанції відповідають такі показники: зріст $-176 \mathrm{~cm} \pm 5,6 \mathrm{~cm}$, вага -61 кг \pm 4 кг, зросто-ваговий індекс $-15,4 \pm 5$ в. о., біг $60 \mathrm{~m}-7,3 \mathrm{c} \pm 0,3 \mathrm{c}$, біг $200 \mathrm{~m}-24,3 \mathrm{c} \pm 1.2 \mathrm{c}$, біг 800 м $-1: 51,7 \pm 2,9$ с, стрибок у довжину 3 місця - 2,64 м $\pm 0,21 \mathrm{м}$, потрійний стрибок з місця $7,77 \mathrm{м} \pm 0,59$ м, біг $5000 \mathrm{м}-14: 10,0$ хв $\pm 0,67 \mathrm{c}$.

3 результатів розрахунку коефіцієнту варіації вбачається, що у 9 показниках із 10 значення не перевищує $10 \%$. Це свідчить про високу однорідність цієї вибірки та високу щільність показників у групі. 3 цього робимо висновок, що для досягнення результату в бігу на 1500 м $3: 44,15$ хв $\pm 4,38$ с насамперед необхідно мати високий рівень розвитку показників швидкісної витривалості та швидкісно-силових якостей. Проте коефіцієнт варіації показника зросто-вагового індексу складає $32 \%$, що вказує на неоднорідность. Тобто зріст, вага та силові показники бігунів високої кваліфікації (МС і вище) не суттєво впливають на результат.

За основу для створення кваліфікаційної моделі фізичної підготовленості висококваліфікованих бігунів на середні дистанції для досягнення результату $3: 44,15 \mathrm{xв} \pm 4,38$ с в бігу на 1500 м були взяті середні значення показників фізичної підготовленості бігунів.

Визначено, що зросто-ваговий індекс разом зі стрибком у довжину, потрійним стрибком і бігом на 5000 м високваліфікованих бігунів на середні дистанції мають найбільшу варіативність щодо інших показників. Значення коефіцієнтів варіації у групі такі: 3ВI (32\%), силові показники в стрибку у довжину з місця та швидкісно-силові У потрійному стрибку (7,8\% і 7,6\%), показник загальної витривалості у бігу на 5000 м (7,9\%).

Наприклад, показник зросто-вагового індексу Миколи Нижника становить більш ніж 300\% від показника Артема Казбана. Однак показник у стрибку в довжину з місця у Артема Казбана є більшим майже на 19\% від показника Миколи Ниж-

Таблиця 1

Показники фізичної підготовленості бігунів на середні дистанції

\begin{tabular}{|c|c|c|c|c|c|c|c|c|c|c|}
\hline Показники & $\begin{array}{l}\text { है } \\
\text { है } \\
\text { के }\end{array}$ & 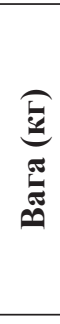 & $\begin{array}{l}\hat{\dot{\theta}} \\
\dot{\hat{\theta}} \\
\stackrel{0}{m}\end{array}$ & 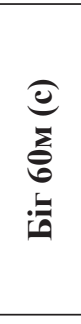 & 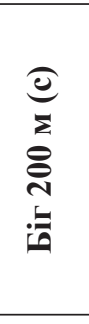 & 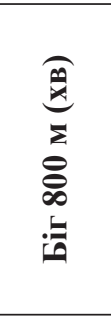 & 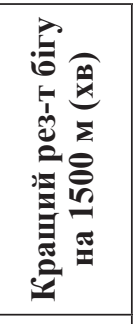 & 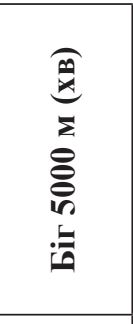 & 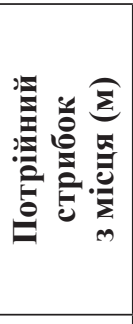 & 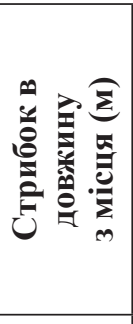 \\
\hline $\begin{array}{c}\text { Киц } \\
\text { Володимир } \\
\end{array}$ & 179 & 62 & 17 & 7,3 & 24,4 & $1: 50,3$ & $3: 38,61$ & $13: 52,0$ & 7,61 & 2,60 \\
\hline $\begin{array}{l}\text { Кіщенко } \\
\text { Юрій }\end{array}$ & 182 & 67 & 15 & 7,1 & 22,8 & $1: 49,6$ & $3: 40,23$ & $14: 25,0$ & 8,32 & 2,85 \\
\hline $\begin{array}{l}\text { Каяфа } \\
\text { Олег }\end{array}$ & 185 & 67 & 18 & 6,9 & 22,2 & $1: 47,5$ & $3: 40,31$ & $14: 50,0$ & 8,64 & 2,95 \\
\hline $\begin{array}{c}\text { Казбан } \\
\text { Артем } \\
\end{array}$ & 169 & 61 & 8 & 7,0 & 22,3 & $1: 48,2$ & $3: 41,90$ & $13: 57,0$ & 8,00 & 2,90 \\
\hline $\begin{array}{c}\text { Стребков } \\
\text { Іван }\end{array}$ & 174 & 57 & 17 & 7,2 & 24,8 & $1: 51,5$ & $3: 43,16$ & $13: 53,0$ & 6,60 & 2,50 \\
\hline $\begin{array}{c}\text { Городиський } \\
\text { Богдан-Іван }\end{array}$ & 178 & 61 & 17 & 7,2 & 23,0 & $1: 52,2$ & $3: 43,99$ & $14: 37,0$ & 8,21 & 2,69 \\
\hline $\begin{array}{l}\text { Вихопень } \\
\text { Юрій }\end{array}$ & 171 & 63 & 8 & 7,3 & 23.5 & $1: 52,8$ & $3: 44,97$ & $14: 03,0$ & 7,93 & 2,62 \\
\hline $\begin{array}{c}\text { Ростикус } \\
\text { Роман }\end{array}$ & 172 & 57 & 15 & 7,4 & 25.0 & $1: 52,8$ & $3: 45,92$ & $14: 08,0$ & 7,80 & 2,55 \\
\hline $\begin{array}{l}\text { Нижник } \\
\text { Микола } \\
\end{array}$ & 182 & 57 & 25 & 7,8 & 25.5 & $1: 56,3$ & $3: 50,11$ & $13: 37,0$ & 7,20 & 2,35 \\
\hline $\begin{array}{l}\text { Шевченко } \\
\text { Сергій }\end{array}$ & 171 & 57 & 14 & 7,2 & 24.5 & $1: 55,8$ & $3: 52,28$ & $14: 19,0$ & 7,47 & 2,40 \\
\hline $\bar{X}$ & 176 & 61 & 15,4 & 7,3 & 24.3 & $1: 51,7$ & $3: 44,15$ & $14: 10,0$ & 7,77 & 2,64 \\
\hline$\sigma$ & $\pm 5,6$ & \pm 4 & \pm 5 & $\pm 0,3$ & \pm 1.2 & \pm 2.9 & $\pm 4,38$ & $\pm 0,67$ & \pm 0.59 & $\pm 0,21$ \\
\hline V\% & 3,2 & 6,5 & 32 & 3,4 & 5 & 2,6 & 2 & 7,9 & 7,6 & 7,8 \\
\hline
\end{tabular}


ника. Швидкісні ж показники групи висококваліфікованих бігунів коливаються не так стрімко (біг на 60 м 0,25 $\pm 3,42$, біг на 200 м 1,19 \pm 5 ). Отже, для виходу на результат 3:44 хв насамперед необхідно розвивати силові показники та показники загальної витривалості.

Слід зазначити, що Микола Нижник, маючи найнижчі швидкісно-силові показники, демонструє найвищі показники загальної витривалості. Визначено, що спортсмени з більшою вагою та меншим 3BI мають вищі показники в силових тестах, наслідком чого зафіксовано збільшення м'язової маси. Для досягнення такого ж результату 3 меншою вагою потрібні нижчі вимоги до силових показників.

Аналізуючи отримані показники одного із найшвидших бігунів на середні та довгі дистанції України за останні 5 років Володимира Кица щодо моделі бігуна на середні дистанції, встановлено, що швидкісно-силовий і силовий показники є дещо нижчими за модельні характеристики. Проте його результати з бігу на 800 м, 1500 м і 5000 м компенсуються високим рівнем загального, спеціального та швидкісного видів витривалості (рис. 1). Слід зазначити, що антропометричні показники (зріст, вага та зросто-ваговий індекс) перевищують модельні характеристики.

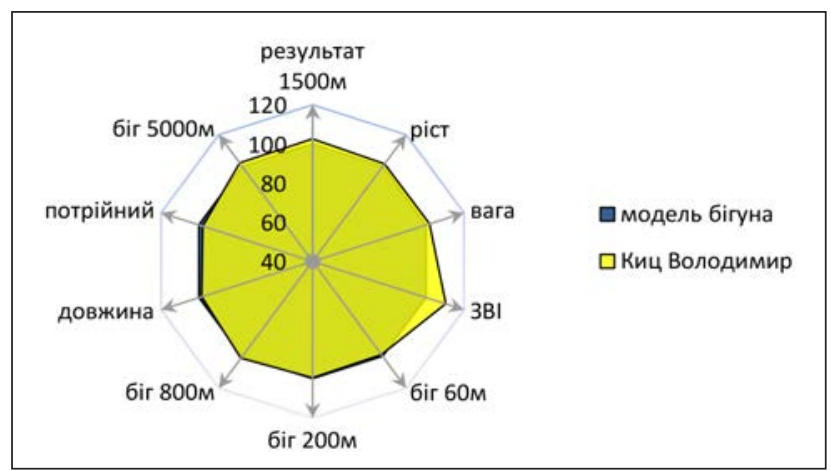

Рис. 1. Індивідуальний профіль фізичної підготовленості В. Кица

Індивідуальний профіль фізичної підготовленості Юрія Кіщенка порівняно 3 характеристиками кваліфікаційної моделі показує, що він має значно вищі показники в низці тестових завдань (зріст, вага, потрійний стрибок 3 місця, стрибок у довжину з місця, бігу на 200 м та 800 м. Показники зросто-вагового індексу та бігу на 5000 м є нижчими за результати модельних (рис. 2).

Показники фізичної підготовленості Олега Каяфи значно вищі за модельні і не мають явно вираженого зсуву в сторону силових, швидкісно-силових чи швидкісних характеристик і розподілені досить рівномірно. Проте результат перевірки загальної витривалості (біг на 5000 м) $є$ досить низьким (рис. 3).

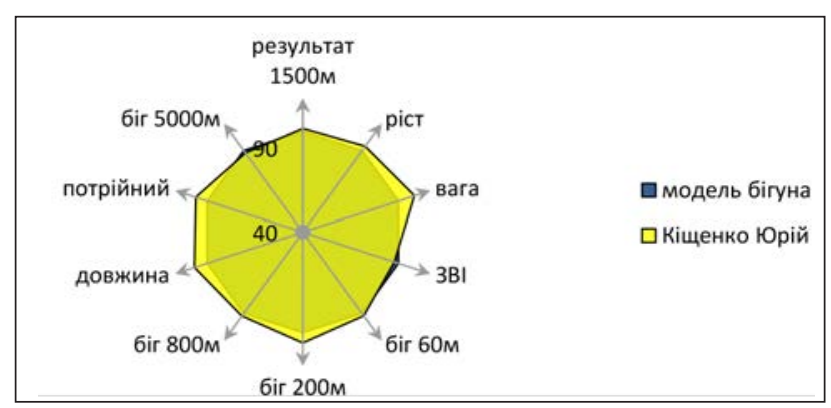

Рис. 2. Індивідуальний профіль фізичної підготовленості Ю. Кіщенка

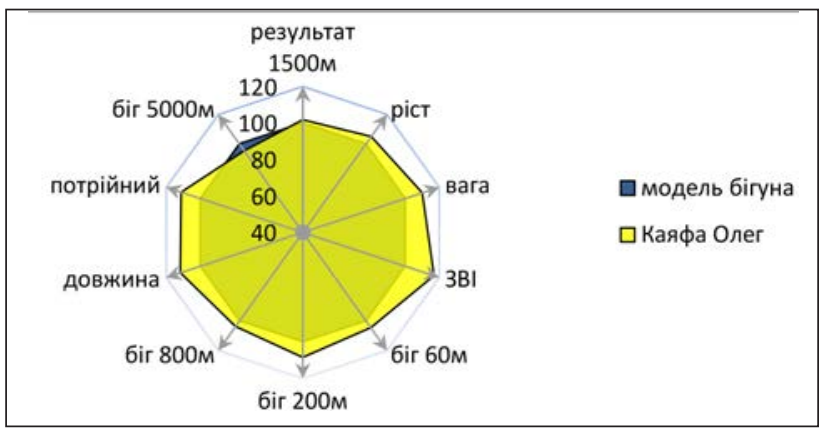

Рис. 3. Індивідуальний профіль фізичної підготовленості О. Каяфи

Аналізуючи показники Артема Казбана, можна стверджувати, що він демонструє досить хороші показники загальної та спеціальної витривалості. Ще кращими є швидкісно-силові показники, але через низький зріст і досить велику м'язову масу спортсмена розрахунок зросто-вагового індексу є найменшим серед усіх спортсменів у групі спостереження. Тому на змаганнях протягом проходження дистанції у спортсмена сформувався силовий біг (рис. 4).

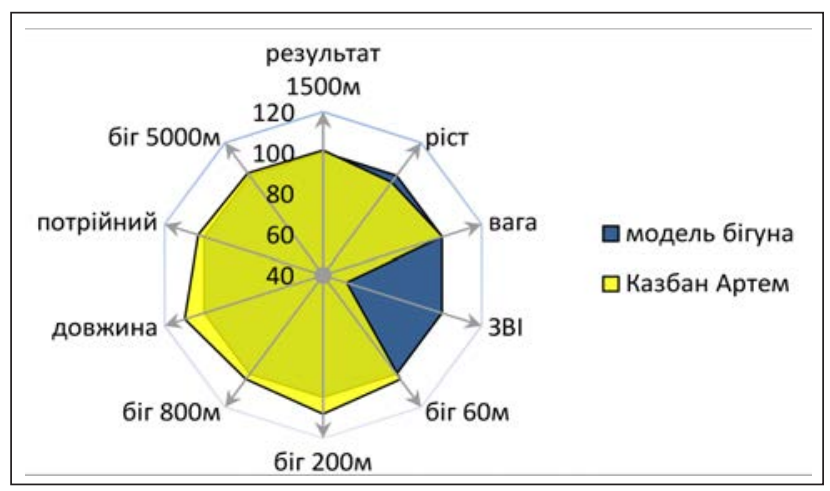

Рис. 4. Індивідуальний профіль фізичної підготовленості А. Казбана

Аналізуючи отримані результати Івана Стребкова, який здебільшого є бігуном на довгі дистанції, можна стверджувати, що спортсмен демонструє досить високі результати на середніх 
дистанціях. Такі показники, як біг на 5000 м, 1500 м, 60 м і 800 м, знаходяться в межах показників кваліфікаційної моделі. Проглядається досить низький показник маси спортсмена, який призвів до високого розрахункового показника зросто-вагового індексу. Проте спортсмен демонструє досить низькі показники стрибка у довжину 3 місця та потрійного стрибка 3 місця (рис. 5).

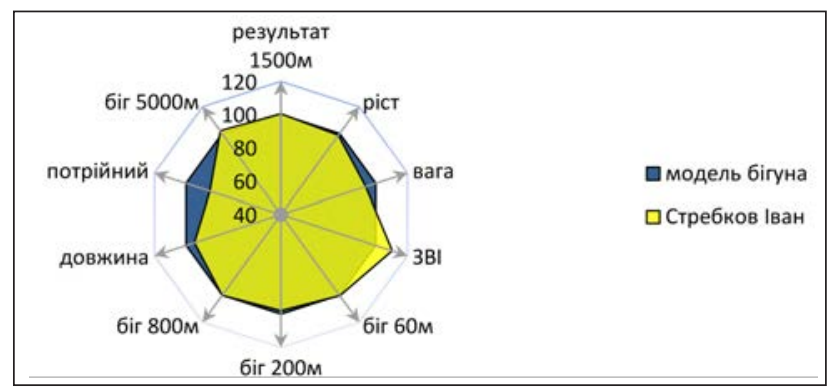

\section{Рис. 5. Індивідуальний профіль фізичної підготовленості І. Стребкова}

Найбільш наближені до модельних характеристик демонструє Богдан-Іван Городиський, маючи досить високий показник зросто-вагового індексу та не менш хороші швидкісно-силові показники. Однак зі всіх тестових завдань спортсменів він має один із найнижчих показників загальної витривалості, що виражається посереднім результатом з бігу на 5000 м (рис. 6).

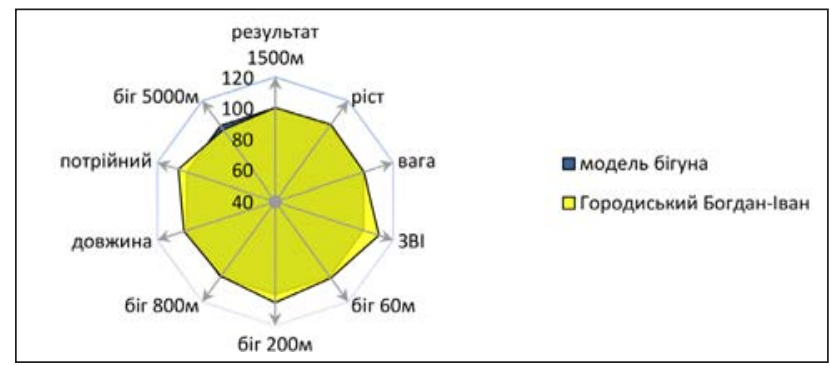

Рис. 6. Індивідуальний профіль фізичної підготовленості Б.-І. Городиського

Аналізуючи показники Юрія Вихопня, бачимо, що вони також є досить близькими до модельних. Слід зазначити, що в Юрія явно виражена досить висока вага порівняно зі зростом, через що у спортсмена розрахунковий показник зросто-вагового індексу значно вищий за модельний показник (рис. 7).

Провівши аналіз результатів Романа Ростикуса, можна стверджувати, що спортсмен спеціалізується в бігу на 3000 м із перешкодам (біг на середні дистанціï). Варто зазначити, що лише два показники (потрійний стрибок із місця та біг на 5000 м) відповідають характеристикам кваліфікаційної моделі. За всіма іншими показниками результати Романа є дещо нижчими (рис. 8).

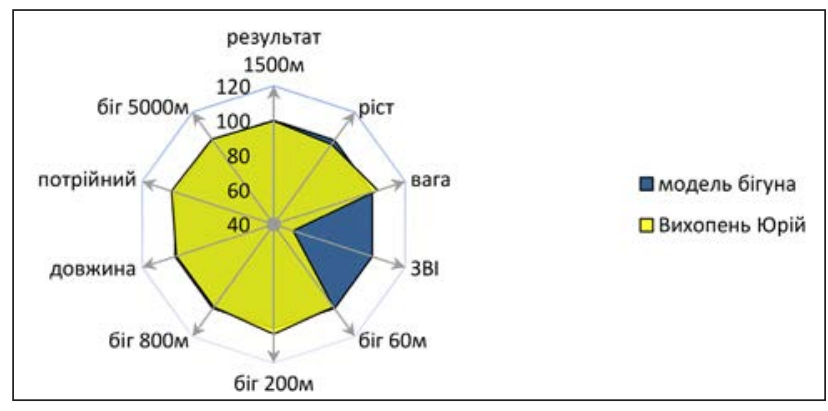

Рис. 7. Індивідуальний профіль фізичної підготовленості Ю. Вихопня

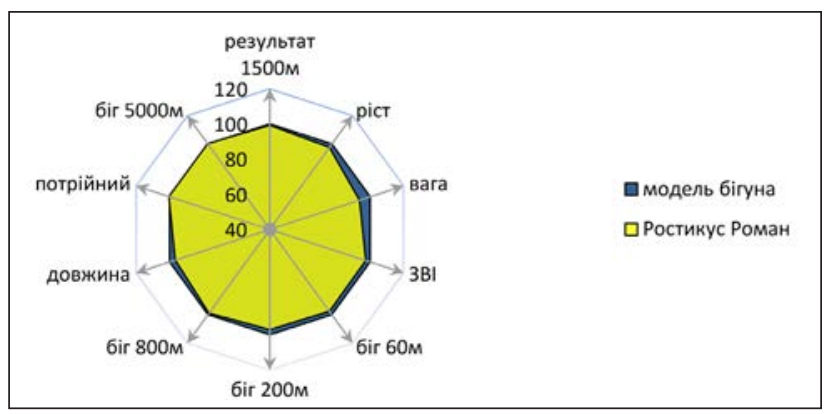

Рис. 8. Індивідуальний профіль фізичної підготовленості Р. Ростикуса

Микола Нижник $є$ типовим представником бігунів на довгі дистанції. Спортсмен демонструє найнижчі показники зі всіх спортсменів у групі спостереження та модельні характеристики у таких тестах: біг на 60 м, 200 м, 800 м, стрибок у довжину з місця, потрійний стрибок із місця. Але через свою низьку вагу та досить високий зріст у спортсмена дуже високий розрахунковий показник зросто-вагового індексу. Не менш вражаючим $€$ показник загальної витривалості, який $є$ найвищим серед усіх спортсменів групи спостереження, що дозволяє спортсмену демонструвати неперевершені результати у бігу на 5000 м, 10000 м і півмарафоні (рис. 9).

Аналізуючи результати проведеного педагогічного спостереження за Сергієм Шевченком, можна стверджувати, що він - наймолодший спортсмен серед групи, але дуже перспективний. Результати, які продемонстрував Сергій, порівняно 3 характеристиками кваліфікаційної моделі $є$ значно нижчими за такими показниками, як біг на 60 м, 200 м, 800 м, 1500 м, 5000 м, стрибок у довжину з місця та потрійний стрибок із місця. 


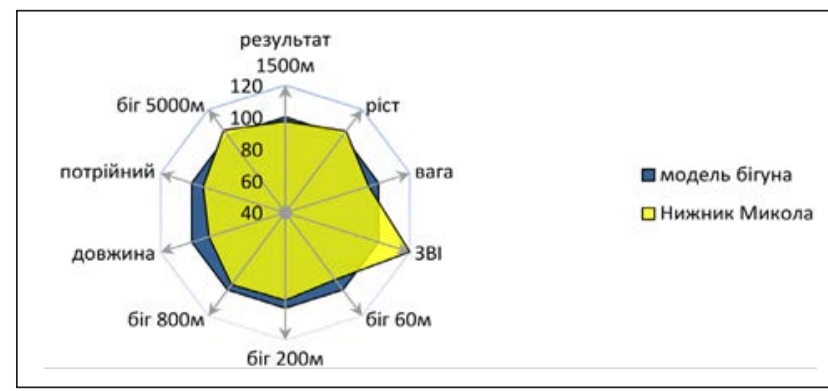

Рис. 9. Індивідуальний профіль фізичної підготовленості М. Нижника

Окрім того, антропометричні показники (зріст, вага та зросто-ваговий індекс) Сергія $є$ також нижчими за модельні (рис. 10). Можемо обгрунтувати такі низькі показники у тестових вправах віком спортсмена, якому ще необхідно працювати над розвитком фізичних якостей, що призведе до покращення особистих досягнень.

Висококваліфіковані бігуни на середні дистанції, які мають більшу вагу та менший 3ВI, здебільшого мають вищі показники в силових і швидкісно-силових вправах за рахунок збільшення м'язової маси (А. Казбан, О. Каяфа, Ю. Вихопень). Для досягнення такого самого результату бігуни 3 меншою вагою можуть мати нижчі силові показники (I. Стребков, М. Нижник, С. Шевченко).

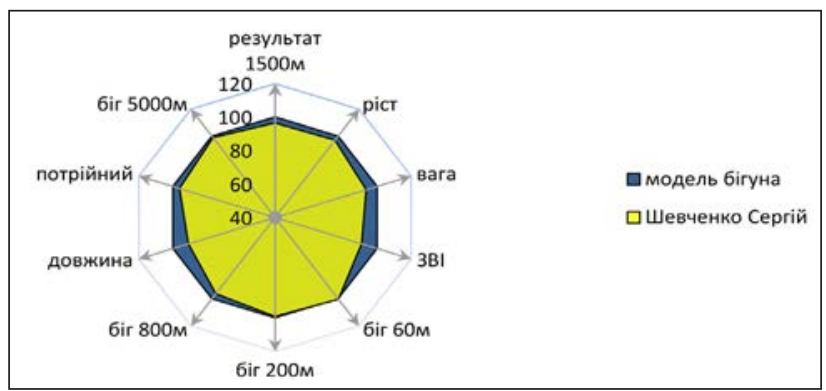

Рис. 10. Індивідуальний профіль фізичної підготовленості С. Шевченка

Отримані результати дозволяють використовувати розроблену модель фізичної підготовленості висококваліфікованих бігунів на середні дистанції в спортивній практиці.

Висновки. У результаті проведеного дослідження розроблено кваліфікаційну модель фізичної підготовленості висококваліфікованих бігунів на 1500 м. Встановлено, що висококваліфіковані бігуни на середні дистанції, які мають більшу вагу та менший 3BI, здебільшого мають вищі показники в силових і швидкісно-силових вправах за рахунок збільшення м'язової маси (А. Казбан, О. Каяфа, Ю. Вихопень). Для досягнення такого самого результату бігуни з меншою вагою можуть мати нижчі силові показники (I. Стребков, М. Нижник, С. Шевченко).

\section{ЛІТЕРАТУРА}

1. Тер-Ованесян И.А. Подготовка легкоатлета: современный взгляд. Москва : Терра-Спорт, 2000. 128 с.

2. Платонов В.Н. Система подготовки в олимпийском спорте. Общая теория и ее практическое применение : учебник в 2 кн. Киев : Олимпийская литература, 2015. 680 с.

3. Маєвська С.М., Гриньків М.Я., Вовканич Л.С., Старостюк Г.К. Модельні характеристики спортсменів окремих видів спорту зі швидкісно-силовою спрямованістю тренувального процесу. Теорія та методика фізичного виховання. 2011. № 3. Харків. С. 36-41.

4. Кузнецов В.В., Петровский В.В., Шустин Б.Н. Модельные характеристики легкоатлетов. Киев : Здоровье, 1979. $88 \mathrm{c}$.

5. Конестяпін В., Ханікянц О., Дем’янюк Д. Показники фізичної підготовленості стрибунів у висоту на етапі максимальної реалізації індивідуальних можливостей. Моделювання та інформаційні технології у фізичному вихованні та спорті : тези доп. XII Міжнар. наук. конф. Львів. 2016. C. 54-56.

6. Ашмарин Б.А. О тестах и тестировании. Физ. культура в шкколе. 1985. № 3. С. 60-62.

\section{REFERENCES}

1. Ter-Ovanesjan I.A. (2000) Podgotovka legkoatleta. [Athlete training]. Modern view. Moscow : Terra-Sport (in Russian).

2. Platonov V.N. (2015) Sistema podgotovki v olimpijskom sporte. Obshhaja teorija i ee prakticheskoe primenenie [Training system in Olympic sports. General theory and its practical application]: a textbook in 2 vols. Kiev : Olympic Literature (in Russian).

3. Majevsjka S.M., Ghrynjkiv M.Ja., Vovkanych L.S., Starostjuk Gh.K. (2011) Modeljni kharakterystyky sportsmeniv okremykh vydiv sportu iz shvydkisno-sylovoju sprjamovanistju trenuvaljnogho procesu [Model characteristics of athletes of certain sports with speed-power orientation of the training process]. Theory and methods of physical education. 2011. Vol 3. Kharkiv. P. 36-41. 
4. Kuznecov V.V., Petrovskij V.V., Shustin B.N. (1979) Model'nye harakteristiki legkoatletov [Model characteristics of athletes]. Kiev : Healthy. 88 p.

5. Konestiapin V., Khanikiants O., Demianiuk D. (2016) Pokaznyky fizychnoi pidhotovlenosti strybuniv u vysotu na etapi maksymalnoi realizatsii indyvidualnykh mozhlyvostei. [Indicators of physical fitness of high jumpers at the stage of maximum realization of individual capabilities]. Modeling and information technology in physical education and sports: thesis add. XII International. Science. conf., Lviv. P. 54-56.

6. Ashmarin B.A. (1985) O testah i testirovanii. Fizicheskaja kul'tura $v$ shkole. [About tests and testing. Phys. culture at school] Vol. 3. P. 60-62. 